\title{
CORRIGENDUM
}

\section{Frobenius n-homomorphisms, transfers and branched coverings}

\author{
BY V. M. BUCHSTABER and E. G. REES
}

Math. Proc. Camb. Phil. Soc. (2008), doi: 10.1017/S0305004107000539;

First published online 17 January 2008

In this paper, the affiliations and names of the authors were misplaced. The correct information is:

\section{V.M. Buchstaber}

Steklov Mathematical Institute, RAS, Gubkina 8, 119991 Moscow

and School of Mathematics, University of Manchester, Manchester M13 9PL.

and E.G. Rees

School of Mathematics, University of Edinburgh, Edinburgh EH9 3JZ and Heilbronn Institute for Mathematical Research, University of Bristol, Bristol BS8 1TW.

The Editor apologises for this error. 